\title{
An Evolving Teaching Methodology: An Integrated Approach To Teaching Multi-Disciplinary Classes
}

Craig Baird, (Email: Craig.Baird@ uwa.edu.au), University of Western Australia, Australia Kerry Pedigo, (Email: K.Pedigo@ curtin.edu.au), Curtin University of Technology, Australia

\begin{abstract}
This paper discusses an approach to teaching and learning in multi-disciplinary university settings using case study based scenarios presented using films as a key teaching methodology. The production of four films (The Video store, Perception Airlines, Tranquil Whispers, and Middleton) over an eight year period was an iterative process through which the use of film-based case study scenarios was refined as a teaching tool to integrate student learning across multiple disciplines in a business school. Each of the four films was designed to enhance first year university students' understanding of theories and practices used in a range of discipline areas that underpin the operations of a commercial business undertaking. The final film mainly discussed here depicts a central case study scenario, entitled 'Middleton' featuring a cast of teaching and academic staff from the Curtin Business School (CBS) in Perth, Western Australia and Curtin Sarawak, Malaysia(Curtin University of Technology). It was produced as a core teaching approach for exploring themes as part of the delivery of several first year units within the CBS, delivered over twelve campuses in Western Australia and South East Asia (Singapore, Malaysia, Hong Kong, Sri Lanka). Students in their first year of a commerce degree study compulsory business units that are disparate in their content and delivery. This diversity can cause some students to have difficulty with defining meaningful cohesiveness between units in their first year of study. 'Middleton' sought to integrate the first year subjects into a film depicting a central case study of an international business operation.
\end{abstract}

\section{INTRODUCTION}

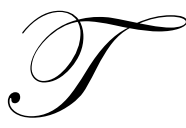

he first of the four purpose-made films that led to the approach to teaching and learning discussed here was called The Video Store. It was written, produced and acted in by academic staff from five different discipline areas within a Business School of a large Australian University (Curtin University of Technology [CUT]). This film sought to integrate student learning experiences from faculties of Law, Accounting, Management, Economics, and Information Systems in a manner that gave students a sense of how each of these areas form essential elements of business and commercial practice. The film and associated learning resources and assessment activities were integrated by the five discipline area unit coordinators in ways that ensured continuity of student learning experiences across the disparate discipline areas.

Collaborative development of the film based approach to teaching and learning was facilitated by having first year unit coordinators working together on a common task affecting each of the discipline areas. This led to a broader understanding of each other's areas such as differences in teaching styles, referencing styles, assessment scheduling and practices. It also highlighted similarities and disparities in course content in what should have been a more coherent first year experience for students in transition (high school or work into university life). In addition, those same faculty members 'starred' in the film thus providing a vehicle for introducing themselves to their students and to other staff visually and as 'human beings' (really bad acting) prepared to have a little fun and not take themselves too seriously by acting in such a film. This provided a mechanism for early identification and bonding for students with their lecturers within the business course. Having a common learning approach used across disciplines also created 
many opportunities for students to interact and network both within their own discipline and within the broader context of the business course.

For many students this assisted their entry to university and enriched their first year experience by having links to staff and other students exploring common themes and learning experiences. Feedback from staff and students who participated in this teaching and learning approach suggests that the methods used gave consistency to the first year experience for students in terms of learning activities, scale and complexity of content, course and unit learning outcomes, common practices in referencing and writing standards.

In the course of creating this film additional learning activities and resources were developed to encourage student development and understanding of the integrated and cohesive nature of the operations of five areas of business. This was achieved through the use of the film backed up with interconnected activities and resources to inform and scaffold learning from multiple discipline perspectives. The film provides a mechanism for linking and binding a related group of disciplines facilitated collaborative opportunities for teaching across different disciplines. This teaching method encouraged a learner centred approach to learning.

Assessment items used by unit coordinators across the five discipline areas were linked to ensure progressive and timely testing and formative feedback on student learning. A key part of the assessment process was for students to have similarity across disciplines (where in the past there had been considerable disparity) in the assessment format and for them to be able to make links through a common theme. This gave students a broader perspective of the overall manner in which multi-discipline business practices interrelate with each other and affect business decisions and outcomes. Using common assessments between disciplines also provided opportunities for collaboration when embedding desired student graduate attributes as elements of course learning outcomes.

The first film, The Video Store, film and associated learning and assessment tools developed for it proved to be a most successful way for linking multiple disciplines for students. Building on what had been learned about the effectiveness of the film-based case study approach as a learning tool, three more films were made by most of the same faculty members. The second film produced was Perception airlines. This was followed by Tranquil Whispers which differed from the first two films in that it was focussed on teaching in the management discipline only. In the following year it was decided that the broader multi-disciplinary approach used in the first two films had provided a wider reach and greater overall benefit to learning. Building on the strengths and learning gleaned from the previous films, it was decided to produce another multi-discipline film, Middleton. The development, production and use of that film is explored here using information gathered using personal interviews and survey questionnaires completed by students and staff who had used the films as part of their teaching and learning.

\section{MIDDLETON}

Middleton is the title of a case-study film depicting a large Western Australian (WA) company about to launch into the wine industry in the South East Asian region. The film depicts the ongoing operational scenarios associated with management, marketing, accounting, economics, business law, and information systems. Middleton was filmed both in Australia and Malaysia so as to embrace a broad view the cultural diversity of the CUT student cohort as well as to represent business issues from two different cultural regions. In doing this, Middleton sought to integrate intended learning outcomes for a number of first year business and commerce subjects into a film depicting a central case study of an international wine industry business operation.

A team of first year unit co-ordinators from six discipline areas collaborated in the development of ideas for key learning scenarios to be depicted in the film. The learning scenarios were then used as a basis upon which to develop a story portraying an international business organisation operating in Australia and Malaysia to produce and market wine. The purpose of the film was to create an innovative teaching tool with realistic situations and examples of typical business scenarios and emergent problems. The film Middleton is a central platform for portraying numerous business activities, decision making procedures, group dynamics, use of interpersonal skills, appropriate behaviours and moral and legal situations typical of what might be found in many business practices. 
Five discipline areas within business and commerce at the CBS used this film between 2003 and 2004 as part of lecture and tutorial class sessions in the commerce degree. For example, in the first year management unit, the film is used in conjunction with a purpose written guide that presents questions based on the situations, problems, and outcomes depicted in the film. The sequence and content of these activities were designed to provide incremental learning about management practices appropriate to the intended learning outcomes set by the unit syllabus. Students were required to analyse various components of the film in small group sessions to determine how they applied to managing the business. Issues and problems portrayed in the film were integrated into classroom-based learning activities designed to assist development of critical thinking and problem solving skills for students.

This following section outlines how faculty members collaborated to facilitate production of the film. It also addresses some of the benefits and highlights of producing this type of learning resource. Discussed are some of the difficulties associated with bringing together faculty members from two different cultural settings and disparate disciplines to develop a film based teaching and learning approach.

\section{USING FILMS TO FACILITATE LEARNING ACTIVITIES IN MULTIPLE DISCIPLINES}

Middleton was produced with the purpose of uniting several disparate discipline areas in which students studying a range of topics in their first year of university learning may not necessarily understand the connectedness between the various topics. For example how do management and marketing issues relate to or impact on accounting practices, or financial concerns, or IT implantation.

In individual discipline areas the film also provides a mechanism for understanding each topic in a practical manner, with real situations and problems enacted. For example, in the management unit, the film provides the basis for establishing of forum for analysing and understanding each aspect of the management course, such as planning, teamwork, motivation, leadership styles, cross-cultural differences and ethical issues. Each week students worked in small teams, called Learning Sets, and problem solved one aspect of the case study depicted in the film based on their learning and understanding of management, and guided by a purpose written learning activities resource booklet (called "Get Set") and prescribed sections of the unit textbook.

\section{A COLLABORATIVE PRODUCTION TEAM APPROACH}

The development, writing and production of the film provided a forum for staff working in diverse facility areas (but teach the same cohort- of students) to collaborate in a community or network in resolving a common superordinate goal. The filming process and integration of the various roles provided a basis for understanding the interrelationships that exist between each of the disciplines and this provided a more coordinate effort in terms of assessment and understanding the demands placed on students. The subsequent collegiality that evolved as just one of the many positive outcomes the emerged during the filming and working together has led to invaluable links between the many staff involved. This is something that cannot be readily replicated in the usual operations of a large multifaceted professional discipline area such as at the CBS.

\section{DEFINING EMBEDDED SCENARIOS TO MATCH MULTIPLE DISCIPLINE CONSTRUCTS}

Each faculty member from the nominated first year discipline areas used as a basis for creating scenarios in the film learning outcome statements from their unit curriculum outlines. This helped them to link key aspects of their subject areas to the film scenarios that could be discussed during class activities and formed part of assessment items. For example, in the film a situation for teaching one aspect of management was built around a scene in which ethical issues in business were introduced by having one character suggest downloading a web page of another companies profile and services. This opened the way to discuss ethical issues such a copyright and plagiarism.

Working in this manner provided many opportunities for lecturers from diverse disciplines within the CBS to ensure that the film was directly linked to their planned teaching and student learning outcomes, activities, and assessments. The was done in such a way as to construct the scenes to be non-specific to particular tasks, but to be sufficiently flexible to allow the film to be used in different ways over several semesters. Thus alternate applications 
of the various scenarios were used to address ongoing multiple problem solving situations in each discipline area. Taking this approach provided opportunities for different discipline constructs to be built into scenes that in themselves portray themes that were applied by faculty to multiple business and commerce applications.

\section{MATCHING SCENARIOS TO EXPERIENTIAL AND TEAM BASED LEARNING ACTIVITIES}

Following on from designing the scenarios to develop themes around multiple discipline constructs, each of the faculty involved in the production of this film set about developing tutorial based experiential learning activities and assessments. The aim was to utilise what students would see in the film as a basis of group-work sessions and collaborative problem solving using situations similar to those depicted in film scenarios. For example, in the workbook "Get Set" (a companion information and task booklet to the film), one such activity required the students to analyse the approach to social responsibility as portrayed in a scene in the film that shows the principal characters discussing the importance of protecting the environment of the "Western Swamp Tortoise" an endangered species in Western Australia. This learning activity is further supported by information that the students are required to source from the prescribed text and research journal articles.

Having six different discipline areas involved in the making of the film led to a broad body of teaching and learning materials being developed from the one principal learning tool. The film acts as a stem for the development of multiple learning and assessment tasks and tutorial session activities that are underpinned by themes thus depicted. One student when commenting on this said:

The film relates with our "Get Set" activities so we are able to work in groups to answer the questions and learn some right ideas like in real life. Also the film showed us some wrong ways of doing things that we discussed so we can avoid doing them in real life such as polycentric.

Comments such as this have helped to inform planning for future production of another similar teaching and learning film.

\section{ORGANISATION OF TEAM MEMBERS - AVAILABILITY ISSUES}

Production of Middleton began with the establishment of a team consisting of six faculty members and four other support staff. Bringing such a large group from diverse discipline areas together to prepare the learning content and script for the film was at times difficult. In order to facilitate an uninterrupted, focussed setting for the filming it was decided to take the group away to a location where there would be no distractions, and all members of the production team were present at all times. This involved an intensive two-day period in Albany (a coastal town in Western Australia) and three days in Miri (Sarawak). Albany provided an ideal location for filming with many local resources such as access to wineries and buildings suitable to represent the types of settings needed to portray business operations. In order to ensure the international and multi-campus value of this film as a Curtin teaching tool two members of the team flew to Miri from Perth to join with Curtin University staff at the local campus there in making scenes that reflected cultural aspects of doing business in that country. This also helped to ensure continuity of one of the film's characters as well as providing exclusivity for our overseas staff in their own teaching setting. Having this additional element in the film provided opportunities for collaborative team building with the Miri staff along with the added feature of being able to have local lecturers acting in settings that for many Curtin students is their home environment and culture.

\section{CHOOSING AND USING THE SETTINGS}

All aspects of the making of this film were dealt with using the same collaborative team-based methods that were depicted in the teaching and learning activities embedded in the script. Together, the production team pooled its knowledge of various contacts and networks that were utilised to access suitable locations both in Albany and Miri. Although much of the planning took place prior to our arrival at the two filming locations, many opportunities that emerged for filming in local business premises and at a winery in Albany, and at a palm oil enterprise in Miri, were seized upon and integrated into the film production. Working in this way a wealth of authentic situations and genuine 
local input were incorporated into the business scenarios thus adding to the reality of the situations depicted. Having authentic settings for creating the learning scenarios was said by the staff who acted in the film to have greatly assisted their depiction of the kinds of roles and characters that they sought to portray. One lecturer commented on his participation:

Being there in the winery really got me thinking about how I was going to use this film in my classroom to explore a number of different concepts in business operations. Playing the role in that setting gave me a real sense of how my students might relate to working as a manager with the kinds of situations that were presented in the film as reflected in the authentic practices of businesses in that region and mode of practice. There was a strong sense of connectedness, collegiality and community of learning in the production team. Being there together fostered a network of support between staff from disparate areas from across the University.

\section{USING THE FILMS IN TEACHING AND LEARNING - FEEDBACK}

Research about Middleton's effectiveness as a teaching and learning tool was undertaken through personal interviews and a student survey questionnaire. Commenting on how the film assisted learning, one student said:

When I relate the topic back in my mind to the film and can infer stuff to real life organisations ... it really helped me to understand the theory stuff better.

Another student said:

It gave me an incite (sic) into group development and how they change over the course of their business cycle.

Throughout 2003 and 2004 Middleton was used in six different discipline areas in the CBS. Students and staff feedback on their perception of the value of using the film as part of a teaching and learning approach was very positive. Other data collected from the assessment of student assignments based on learning scenarios incorporated in the Middleton film indicate that the film provided an excellent mechanism for analysing many different aspects of business operations including appropriate ethical and culturally aware practices. Commenting on how the film assisting learning in multiple unit areas, one student said:

...it's adaptable to each subject in the degree that I am doing. By studying it for Marketing it has helped me in Management also ... I am able to get a better understanding of both subjects because I have seen them in the film and now understand how they go together.

\section{CONCLUSION}

Overall the authors regard the making and implementation of the four films, and in particular Middleton, to be a great success on many levels. It brought together a group of academic and support staff in a unique team that has continued to work collaboratively since the productions and this has led to a more unified and integrated approach to teaching and learning in the first year of University life for business students at CUT. As a teaching approach the films have provided a versatile platform upon which each of the academic staff from the six discipline areas has been able to build a range of flexible learning activities and assessments that link to the common themes and constructs that together form business and commerce. The extension of the community of teaching and learning that has grown out of this collaborative undertaking and has already added to the collegiality and collaborative approach taken by having first year discipline areas linked by common themes in learning and assessment activities.

For further information and details please contact Professor Kerry Pedigo at the Curtin University of Technology in Perth, Australia or Professor Craig Baird at the University of Western Australia in Crawley, Australia. 
NOTES 